\title{
Big Data Analytics for Improving Financial Performance and Sustainability
}

\author{
Xiangyu ZHU \\ School of Economics and Management, Beijing University of Technology, Beijing 100124, China \\ E-mail: zhuxiangyu@bjut.edu.cn \\ Yang YANG \\ School of Economics and Management, Beijing University of Technology, Beijing 100124, China \\ E-mail: S201811068@emails.bjut.edu.cn
}

\begin{abstract}
In this study, the key drivers of sustainability commitment, green supply chain management, big data integration and green human resource practice are explored, and the impact of these sustainable capabilities on the environmental and financial performance of banks is also elaborated. In addition, the influence of green management practices on integrating big data technology into operations is presented. As for the concept of dynamic ability, it has been used to recommend and empirically test conceptual models. Data were collected through a self-administrated survey questionnaire on 317 people working in 37 banks in six Asian countries. Research suggests that big data analytics strategies have an impact on internal processes and on the stability and financial performance of banks. Besides, it is indicated that banks are committed to proper data monitoring of their customers to complete operational efficiency and sustainability goals. Furthermore, our result proved that banks practicing Green Innovation strategies experience better environmental and economic performance because their employees are already trained in Green HR. Finally, from our study, it was found that internal and external green supply chain management practices have a positive effect on the environmental and financial performance of banks, thus ensuring that the bank of Association of Southeast Asian Nations (ASEAN) mitigates the environmental impact through its operations and ultimately experiences an increase in financial performance.
\end{abstract}

Keywords financial performance; sustainability; big data analytics; banks; green management

\section{Introduction}

The rise of Big Data (BD) brings the financial innovation opportunities as well as challenges ${ }^{[1]}$. The advent of BD has brought solace for humans and societies in numerous ways. In particular, modern-day uncertainties confronted by human beings can effectively be reduced using $\mathrm{BD}^{[2]}$ that is going to stay. However, its Environmental and Social (E\&S) consequences and the sustainability of BD should be further investigated ${ }^{[3]}$. Corbett ${ }^{[4]}$ contends that the revelation of $\mathrm{BD}$ revolution has created new opportunities by increasing the awareness of E\&S impacts on supply chains and the concomitant potential to improve along these dimensions.

BD potentially affects the businesses that warrant an analysis on the implications visvis organizational response, prospects, and challenges of environmentally-sustainable business

Received January 15, 2021, accepted March 28, 2021 
operations ${ }^{[5]}$. The traditional methods of acquiring, accessing and analyzing BD have become obsolete as these methods do not fit with the modern-day requirements of processing $\mathrm{BD}^{[6]}$. Nonetheless, firms' internal environment such as competencies and internal progressions through which Big Data Analytics (BDAs) can be adopted to develop strategies aiming to achieve higher performance remains unexplored. Additionally, most of the studies on enhancing Sustainable Capabilities (SCs) through BDAs concentrate on the manufacturing industry ${ }^{[7,8]}$. It should be mentioned that there is a dearth of studies on enhancing SCs through BDAs despite the significance of the finance sector in developing post-2015 development agendas highlighted in the World Bank Billions to Trillions report (WWF Sustainable Finance Report, 2017).

Intriguingly, a firm is unable to develop SCs without assimilating the effective management of BD along with green human resource management (GHRM) and green supply chain management (GSCM $)^{[8]}$. The existing studies on SCs of banks focus on customer perception of banks corporate social responsibility initiatives, trustworthiness, and staff expertise as an instrument of SCs ${ }^{[9,10]}$. Additionally, current literature on sustainability has identified significant gaps, which are an obstacle to becoming a sustainable bank through corporate commitment and $\operatorname{GSCM}^{[8,11]}$. There is a fact that Asian banks are less conducive to sustainability efforts when compared with European and other Western banks, and the lack of common matrices to measure sustainability in the finance sector also requires deep analyses on the idea presented in this study (World Economic Forum, 2019).

In this study, it is proposed that through the integration of resources for developing SCs, banks can maximize sustainable performance, which entirely concentrates on banks commitment to corroborating sustainable initiatives and BD management at operational and strategic levels. It is achievable by adopting a comprehensive and feasible process by policymakers to guarantee returns on investment in BD projects ${ }^{[12]}$. With this study, the past studies on developing SCs in the manufacturing sector such as $[7,13,14]$ and the finance sector such as $[9,10]$ are augmented. In particular, in this study, the subsequent questions are investigated.

How do banks SCs established on their commitment and resulting in the integration of Big Data Technology (BDT), GHRM practices, and GSCM improve their environmental and operational performance?

How do GHRM practices impact on the integration of BDT, which alternatively improves the sustainable and operational performance of the banks?

The remaining paper proceeds as follows: Section 2 empirically reviews the literature and the underlying theoretical framework. Section 3 develops the conceptual model and hypotheses of this study and covers the research methodology adopted. Section 4 discusses the findings and results. Lastly, Section 5 presents the discussion and conclusion along with implications, limitations and suggestions for future studies.

\section{Literature Review}

\subsection{Big Data Analytics (BDAs)}

In the literature, it is defined as the creation of architectures designed and new technologies and to economically extract value from a large volume of data by capturing high velocity, discovery and/or analysis ${ }^{[15]}$. BDAs has attracted the attention of policymakers over the years 
to direct organizational decision-making [16]. A large number of firms have accelerated their BDAs initiatives to gain a critical insight into achieving competitive advantage. Practitioners and scholars have categorized BDAs as a prospective frontier for innovation, competition, and productivity ${ }^{[17]}$. However, some regarded it as a revolution that will transform the way of living, working, and thinking. Pertaining to the expansion of data volume, velocity, and variety, numerous efforts were made to store, analyze and visualize the data. Whereas, empirical evidence on the impact of BDAs on sustainable performance in the finance sector and the mechanism through which it helps to achieve competitive advantage for banks is still at a rudimentary state $^{[18]}$, which is surprising following the narrative that corporates these days surge to venture in the area of $\mathrm{BDAs}^{[19]}$.

\subsection{Navigating BDAs in the Financial Sector}

BDAs emergence transformed the corporates production and operation modes. Numerous large firms aim to develop SCs through BDAs to achieve market competitiveness for its survival ${ }^{[20]}$. BDAs helps firms use advance analytical skills to obtain quality information from $\mathrm{BD}$, which enables firms to achieve higher operational efficiency and sustainable performance. BDAs assures superior performance for the organizations genuine commitment. According to Mckinsey \& Company Global Banking Report (2018), corporations that are analytically more driven experience three times higher growth when compared with the less driven competitors. The banking industry is among the pioneers of leveraging BDAs among all other industries such as pharmaceuticals, insurance, energy, manufacturing, and agriculture. Yet, the banking industry is unable to fully embed BDAs into its culture, decision processes, and business operations (Mckinsey \& Company Global Banking Report, 2018).

BDAs has become an essential tool for the banking industry in the detection of fraud and prevention of financial crime, credit risk management, and marketing purposes. These days, banks are shifting from product-centric to customer-centric business models, which were achieved through BDAs. For example, one of the largest Singapore-Malaysia banks, the overseas Chinese banking corporation (OCBC), has successfully analyzed historic customer data to determine their preferences (IBM Global Business Services Report, 2013). BDAs is also playing a significant role in financial inclusion, micro financing and customer creditworthiness analysis by processing structured and unstructured consumer data gathered from channels.

\subsection{SCs of ASEAN Banks Through BDAs}

The socio-economic livelihood of 650 million people in Asian countries is at considerable risk due to climate change, which is projected to result in a loss of around 6.7 percent of regional GDP by 2100 (WWF Sustainable Finance Report, 2017). The E\&S risks in the Asian region have reached an alarming level. For example, Southeast Asia only emits $12 \%$ of the global greenhouse gas due to large-scale usage of fossil fuels (International Environment Agency, 2015). The social impacts on Asia could lead to one billion migrants in Asia Pacific, 13 million to 94 million people affected due to floods in South Asia, and 100 million people affected because of decline in coral reef fisheries.

Asian banks use BDAs to develop sustainable finance regulations, guidelines, and strategies for the purpose of advising banks to consider E\&S issues. A few banks in Asia have employed 
BDAs to analyze specific E\&S risks that might impact customers and clearly address sustainability issues. ASEAN banks have also deployed BDAs to strengthen their corporate governance structure and further harmonize sustainable finance regulations across the region. Banks establish formal and informal channels to engage stakeholders and transparently communicate sustainability goals, action, best practices, performance data, and sustainability matrices at regular intervals, which enhances the visibility and credibility of a bank.

\section{Research Design and Methods}

\subsection{The Hypotheses}

This study is built upon the theoretical lens of Dynamic Capabilities (DCs), which investigates the internal and external competency changes through integration and reconfiguration ${ }^{[21]}$. Managers handling operations of non-linear market face organizational challenges that heavily rely on existing knowledge and experience ${ }^{[22]}$, which leads to innovation and urges leaders to recognize their knowledge through realistic data, cross-functional affiliations, and other available communication tools, which can be used to influence the sustainable development in a region.

The assimilation, acceptance, and reutilization of BD influence the banks operational activities, enhance stakeholders interest in such technologies, and strengthen the banks governance system through integration of the technologies ${ }^{[23]}$. Similarly, environmental disclosure information helps corporations attract stakeholders and improve their social responsibility ${ }^{[24]}$. The assimilation process is concerned with the banks integration and extension of its processes and practices to achieve its goals and objectives ${ }^{[25]}$. BDAs deploys distinct capability of information processing for value creation to enhance the competitive advantage of a bank and seek top management support and commitment. The proceeding argument leads to the development of following hypotheses:

H1. Banks commitment positively affects acceptance, reutilization, and assimilation of BD.

Banks supply-chain practices and performance can be additionally improved through the assimilation, acceptance, and reutilization of big data and resources such as information sharing, connectivity, and corporate commitment ${ }^{[26]}$. Banks have the obligation of utilizing and sustainably managing resources due to changes in market conditions and depletion of resources.

Practicing these environmental management activities is supported through the greening of SCM, technology, and innovation, which should be encouraged by policy-makers and bank commitment. GI is a key strategic factor as it supports sustainable development by using technologically innovative methods of energy conservation, waste recycling, and pollution prevention ${ }^{[27]}$. The innovative practices (internal supply chain management) and its implementation are executed by collaborating with all supply chain partners of the banks ${ }^{[28]}$. To build a sustainability supporting system, it is mandatory for all the suppliers of the banks to embrace environmental requirements for both customers and the banks. When suppliers continue to meet environmental requirements, green product innovation increases ${ }^{[27]}$, which directly improves banks competitive advantage and Environmental Performance (EP). Additionally, GSCM emerges as an environment preservation strategy, which collectively lifts EP of the bank and the entire supply chain. Consequently, it is predicted that: 
H2. Banks commitment positively affects internal and external GSCM practices.

It is challenging for policymakers to generate and collect a large volume of data, as it requires strategic decision-making to extract the hidden and actual value ${ }^{[29]}$. In an industrialized world where the market is unpredictable, it becomes challenging for the financial institutions to mitigate the right mix of technology. BD provides a groundbreaking opportunity for businesses, particularly in the service sector, where it increases productivity and Financial Performance (FP). Using BDAs in banks SCM context can be understood by a framework developed by [26], as SCM is one of the key areas, which can affect a business that relies on large data analytics. Operational excellence and competitive advantage of banks can be achieved through the transformation from regular SCM to practicing GSCM. Based on the proceeding discussion, it is posited that:

H3. The assimilation of BD through acceptance and reutilization has a positively effect on internal GSCM practices of the bank.

Past studies indicate the association of several challenges with a large volume of data as it is highly diverse and comes in high velocity, which is challenging for environmental theories and methods. Therefore, these theories become inapplicable due to the lack of accuracy and consistency ${ }^{[30]}$. BDAs positively influences information sharing, customer service management, customer demand management, and environmental management ${ }^{[31]}$. Moreover, from previous studies, the capability of BDAs to reduce carbon emission ${ }^{[32]}$ and increase the economic performance $^{[33]}$ and E\&S performance ${ }^{[30]}$ can be seen. The regulatory bodies in financial institutions are continuously struggling to handle the dynamic shift in the market due to disruption of digital currencies. Furthermore, climate change creates vibrant opportunities for business organizations, and besides, the way of doing business can be transformed through BDAs provided organizations continuously focus on sustainable environmental performance. Hence, it is predicted that:

H4. The assimilation of BD through acceptance and reutilization positively affects the environmental and bank performance.

The adoption of green banking is the result of green innovations, which helps the banks to achieve sustainable development goals such as conservation of energy, recycling of waste, and prevention of pollution ${ }^{[34]}$. Socially responsible financial institutions focus on the creation of jobs, rural and urban development, and environmental issue solving ${ }^{[35]}$. The success of implementing green innovation at the workplace relies on corporate commitment and environmental ethics. Corporations design its GSCM practices in the way that decreases the footprints on the environment and enhances its operational performance. In addition to that, from previous studies, it was discovered that banks GSCM and environmental disclosure have a direct impact on their environmental performance (WWF Sustainable Finance Report, 2017) which leads to the development of aligning and leveraging GSCM for disclosure practice effectiveness, thus further enhancing banks Environmental and Financial Performance (EFP). Hence, here, it is argued that green SCM practices, such as interaction with customers and green purchasing on banks EP, and green collaboration with suppliers and green innovation processes may enhance banks competitiveness in the dynamic market. In lieu of this argument, it is hypothesized that:

H5. Internal and external GSCM practices positively influence environmental and bank 
performance.

While assimilating $\mathrm{BD}$, there are several GSCM, internal and external supply partners, and sustainable practice challenges. Intriguingly, generally, firms having specialized and skilled CEOs are featured with better performance ${ }^{[36]}$. Moreover, these challenges are manageable through GHR practices and corporate commitment, which focus on enhancing environmental and organizational performance ${ }^{[23]}$. From the study, it has been found that organizational internal motivations have a direct impact on GSCM, and definitely have a relationship with corporate commitment and influence while implementing green standards ${ }^{[37]}$. Moreover, green technology, policies and practices of going green, and EP are positively related. Hence, it is inferred that practicing GHR facilitates the adoption of green management, green technologies, and green management. In this case, it is assumed that practicing green HR not only facilitates the banks sustainability, but also enhances its financial performance.

H6. Green HR practices and training influence BD acceptance on reutilization, GSC collaboration on internal GSCM, and internal GSCM on environmental and banks' performance. These hypotheses and the arguments discussed above are outlined in the conceptual model of this study, as shown in Figure 1.

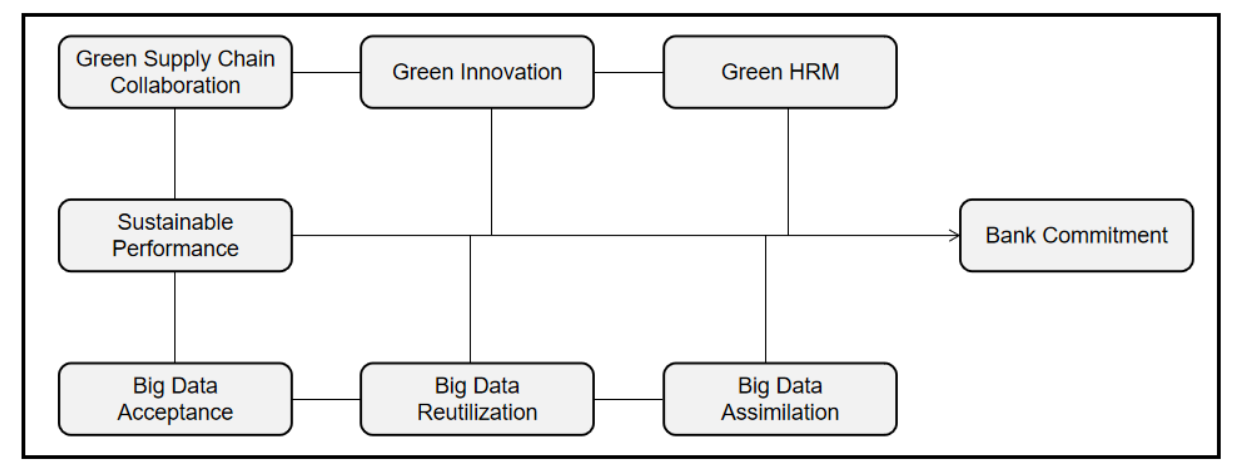

Figure 1 Conceptual model of the research

\subsection{Data Sources}

\subsubsection{Survey and Data Collection}

In this study, the impact of large data driven strategy on banks' sustainable performance is analyzed through internal operations that depict SCs. Additionally, the current study further examines the relationship among BD assimilations, internal and external GSCM practices, banks' sustainable performance (environmental and financial), and the impact of policymakers' commitment. Moreover, the impact of mediating variables such as GHR, particularly green training and practices, on the above variables is also presented in our study. The hypotheses and the predicted relationships were measured through a self-administrated survey questionnaire.

\subsubsection{Questionnaire Content}

The questionnaire comprised two sections, namely, A and B. To be specific, Section A contained the demographics of the respondents; Section B consisted of 11 variables that are 
collectively composed of 50 items that were self-constructed and were adjusted accordingly to achieve the objectives of this study.

Bank commitment (BCMT) contained five items adopted from [38]; big data acceptance (BDACP) comprised three items extracted from [25]; big data reutilization (BDRT) had five items adopted from [25]; big data assimilations (BDAS) involved four items borrowed from [25, 38]; green supply chain collaboration (GSCC) consisted of four items adopted from [24]; green process innovation (GPCINV) included five items adopted from [24]; green product innovation (GPINV) covered four items adopted from [24], while green human resource training (GHRTR) was constituted by five items adopted from [39]. Similarly, green human resource practices (GHRPR) contained five items adopted from [40] and six items adopted from [41] measured environmental performance (EP), and the bank performance (BP) was measured through four items adopted from [42]. The respondents were provided with a 5-point Likert scale (strongly disagree $=1$ to strongly agree $=5$ ) to respond to the items listed in Section B.

\subsubsection{Questionnaire Administration}

Before circulation of the actual questionnaire, a pilot test was conducted through the feedback from three university professors and three industry experts to enhance the relevance and accuracy of the questionnaire content. The target population consisted of employees and managers who were employed in the banks and had prior experience of using BDAs to carry out sustainable initiatives. Since the target population is known to the researchers, a non-random convenience sampling technique is rendered as the most reliable method for data collection purpose. The respondents were formally approached and requested to participate in the online survey. A total of 375 potential respondents in 37 banks located in six different ASEAN countries (Singapore, Malaysia, Indonesia, Philippines, Vietnam, and Thailand) were requested to respond to the questionnaire.

The respondents returned 338 completed questionnaires, indicating a return rate of $89.94 \%$. However, for the actual analysis, 317 samples were considered suitable, as 21 samples were not completely filled in. Besides, 15 participants were contacted to check for non-response bias, and participants were also requested to disclose the reasons for not participating in the survey. Then, it was discovered that the main reason for not participating in was their little understanding of the variables used in our study. A chi-square test is performed on demographic values to compare between early respondents (the participants who returned the questioners within the first two weeks of receipt of the questionnaire) and late respondents (unable to return the questionnaires within 14 24 days). However, it is found that there is no any significant difference between early and late respondents, which confirms that our study is free from issues of non-response bias.

\subsection{Research Methods}

The collected data is analysed through partial least squares structural equation modeling (PLS-SEM) using Smart PLS3.0 to test the hypotheses of this study. The technique mentioned above is more reliable compared with traditional covariance-based SEM as it requires a large sample size ${ }^{[42]}$. Moreover, it is a reliable technique as it accurately estimates the complicated 
hierarchical models containing the assumptions from the soft model. The past studies have vigorously applied this method to test the complex models of BDAs in the business domain ${ }^{[43,44]}$.

Endogenetic latent variables are represented by $\mu$, i.e., the latent variables or factors determined by the internal variables of the model. The endogenous explicit variable is denoted by $y$. $\xi$ refers to the exogenous potential variable, which is determined by variables outside the model. Exogenous explicit variables are indicated by $x$. Endophytic latent variables were EP $\left(\mu_{1}\right)$ and $\operatorname{BP}\left(\mu_{2}\right)$. Exogenous latent variables are $\operatorname{BDACP}\left(\xi_{1}\right), \operatorname{BDRTN}\left(\xi_{2}\right), \operatorname{BDASM}\left(\xi_{3}\right)$, GSCC $\left(\xi_{4}\right)$ and GPCINV $\left(\xi_{5}\right)$. Besides, the following is structural equations concerning latent variables:

$$
\mu=B \mu+\Gamma \xi+\zeta .
$$

Equation (1) reflects the relation between latent variables, when $B$ and $\Gamma$ for the coefficient matrix of the endogenous and exogenous latent variables, and $\zeta$ for error vector regression residuals.

$$
\begin{aligned}
& Y=\Lambda_{Y} \mu+\varepsilon, \\
& X=\Lambda_{X} \xi+\delta .
\end{aligned}
$$

Equation (2) represents the relationship between endogenous explicit variables $Y$ (EP1 EP6, BP1 BP4) and endogenous latent variables. Equation (3) expresses the relationship between exogenous explicit variables $X$ (BDACP1 BDACP3, BDRTN1 BDRTN5, BDASM1 BDASM4, GSCC1 GSCC5, GPCINV1 GPCINV2) and exogenous latent variables, when $\Lambda_{X}$ and $\Lambda_{Y}$ for the factor loading, and $\delta$ and $\varepsilon$ for measurement error.

The covariance matrix of the explicit variables $\left(Y^{\prime}, X^{\prime}\right)^{\prime}$ can be derived from the above parameters.

$$
\sum(\theta)=\left[\begin{array}{cc}
\sum_{Y Y}(\theta) & \sum_{Y X}(\theta) \\
\sum_{X Y}(\theta) & \sum_{X X}(\theta)
\end{array}\right]=\left[\begin{array}{cc}
\Lambda_{Y} B\left(\Gamma \Phi \Gamma^{\prime}+\Psi\right) B^{\prime} \Lambda_{Y}^{\prime}+\Theta_{\varepsilon} & \Lambda_{Y} B \Gamma \Phi \Lambda_{X}^{\prime} \\
\Lambda_{X} \Phi \Gamma^{\prime} B^{\prime} \Lambda_{Y}^{\prime} & \Lambda_{X} \Phi \Lambda_{X}^{\prime}+\Theta_{\delta}
\end{array}\right],
$$

$\Phi$ is the covariance matrix of the latent variable $\xi ; \Psi$ is the covariance matrix of the residual term $\zeta ; \Theta_{\varepsilon}$ is the covariance matrix of $\varepsilon$, and $\Theta_{\delta}$ is the covariance matrix of $\delta$. If the theoretical model is true, then $\sum(\theta)$ is equal to the population covariance matrix $\sum$; i.e., $\sum=\sum(\theta)$, so the variance and covariance of the explicit variables are functions of the model parameters.

PLS-SEM is a two-stage process, validation of the outer model and estimation of inner model path coefficients. The outer model validation is developed by estimating the reliability of coefficient constructs along with their convergent discriminant validity. After measuring the outer model validation, we inserted the inner model to measure the path coefficients. The bootstrap method was used to analyze the significance of findings, while the mediating role of green HRM practices and training was analyzed through multi-group analysis, accomplished by performing cluster analysis, a method used for the segregation of the respondents banks based on their HR practices. The cluster analysis helps group these banks into clusters as proposed by [45]. The cluster analysis was also made to observe the groups following the characteristics of the latent variables. Furthermore, a multi group analysis was performed as suggested by [43] to estimate the significant difference in the path coefficients across the groups. 


\section{Results and Findings}

\subsection{Analysis of the Outer Model}

A model of measure applying factorial analysis. With this model, the consistency and strength of theoretical constructs can be observed. Those constructs can be composed by reflective or formative indicators. In our model, all of them, with the exception of the firms performance, are generated from formative variables.

A structural model to analyze the causality interactions between independent constructs (exogenous) and dependent ones (endogenous). PLS technique is applied multiple times to determine optimal SEM by eliminating least valid observations and further improve statistics of the model.

Regression results of final SEM are demonstrated in Figure 2. Testing results of statistics in the final SEM are all satisfactory. Chiquare/df $=1.979(<3) ; \mathrm{RMSEA}=0.051(<0.08)$; CFI $=0.960(>0.95) ;$ GFI $=0.927(>0.9) ;$ TLI $=0.948(>0.9)$, which proves that the model is valid and regression results are reliable ${ }^{[46]}$. In order to evaluate the consistency of the measure model, we perform the following tests.

Composite reliability. It is used to test internal consistency. The criterion implies that

$$
P_{c}=\frac{\left(\sum \lambda_{i}\right)^{2}}{\left(\sum \lambda_{i}\right)^{2}+\sum_{i} \operatorname{var}\left(\varepsilon_{i}\right)}
$$

is bigger than 0.7, where $\lambda_{i}$ is the standardized load of indicator $i ; \varepsilon_{i}$ is measurement error and $\operatorname{var}\left(\varepsilon_{i}\right)=1-\lambda_{i}^{2}$. In our case, the values obtained are shown in Table 1 .

Table 1 Reliability and validity of constructs

\begin{tabular}{lccc}
\hline Variables & Cronbachs alpha & Composite reliability & Average variance extracted (AVE) \\
\hline BDACP & 0.625 & 0.814 & 0.568 \\
BDASM & 0.723 & 0.865 & 0.589 \\
BDRTN & 0.742 & 0.855 & 0.607 \\
BCMT & 0.826 & 0.901 & 0.670 \\
EP & 0.816 & 0.865 & 0.689 \\
BDASM & 0.782 & 0.889 & 0.655 \\
\hline
\end{tabular}

Convergent validity. Average variance extracted (AVE) proposed by Fornell and Larcker ${ }^{[47]}$ is employed. The value of the expression

$$
\mathrm{AVE}=\frac{\left(\sum \mu_{i}\right)^{2}}{\left(\sum \mu_{i}\right)^{2}+\sum_{i} \operatorname{var}\left(\varepsilon_{i}\right)}
$$

should be bigger than 0.5 , since more of $50 \%$ of construct variance should be explained by its variables. In our study, the value is 0.839 .

The test results of the factor loadings are presented in Figure 2, which indicates that the value of each item is greater than (0.70), the minimum threshold value of acceptable convergent validity. Therefore, the adopted variables determine the significant variance in all the observed variables ${ }^{[48]}$. Additionally, the bootstrap method further confirmed the significance of the factor loading as the value is significant at 0.01 level. 


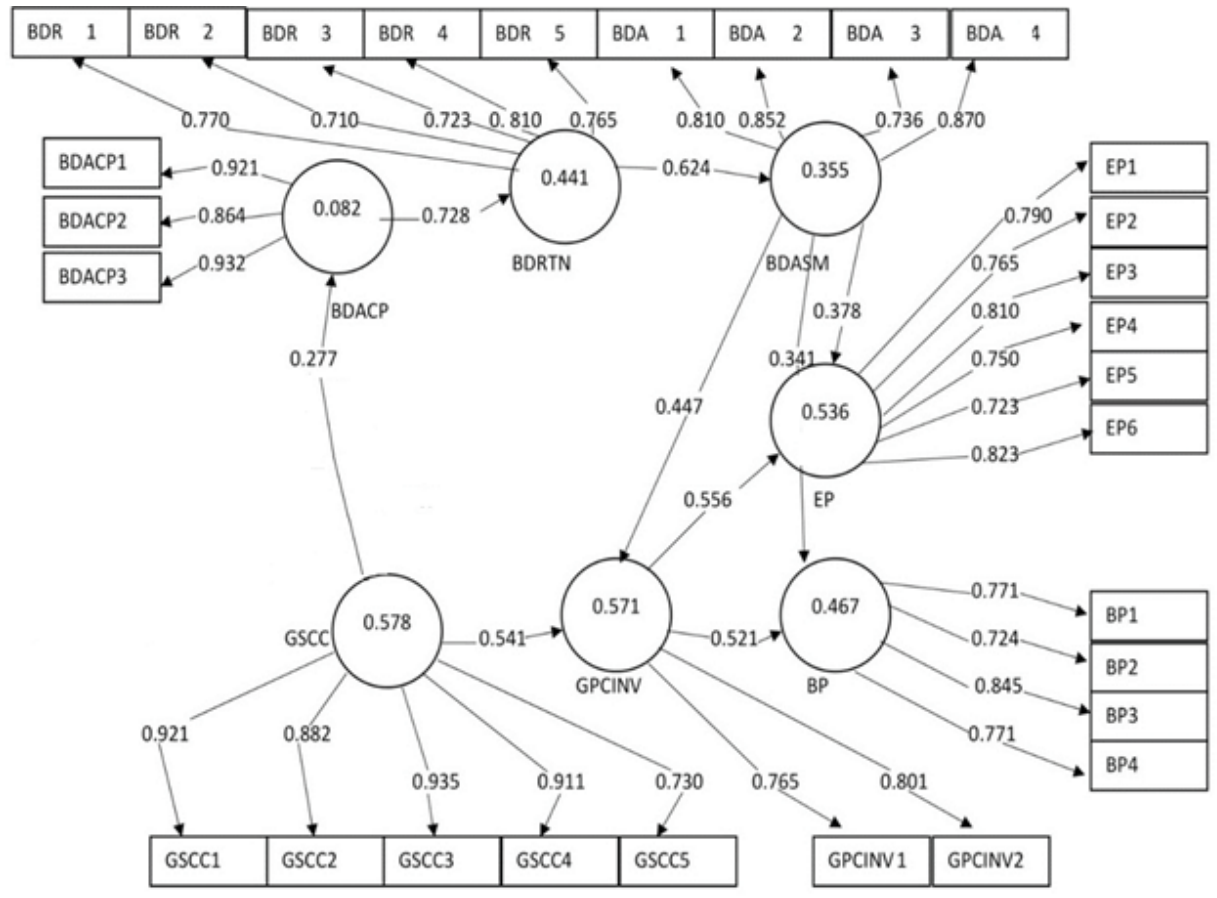

Figure 2 Conceptual model of the research

The results of reliability and average variance extracted (AVE) are presented in Table 1. The reliability test was performed to estimate Cronbachs alpha coefficients and scale composite reliability. The results show that the Cronbachs alpha coefficient value of each construct is greater than the minimum cut-off value (0.70), which suggested that each construct of our study was one-dimensional with reflective properties, and contained high-scale reliability. AVE values of each construct are $>0.50$, which confirms the discriminant validity as the AVE of each variable is greater than the variance of other variables in our study ${ }^{[47]}$. Table 2 indicates the results of discriminant validity which depicts that the diagonal values are greater compared with any of the values in the consistent columns and rows.

Table 2 Discriminant validity results

\begin{tabular}{lcccccccc}
\hline Variables & BDACP & BDASM & BDRTN & BCMT & EP & GPCINV & GSCC & BP \\
\hline BDACP & 0.752 & & & & & & & \\
BDASM & 0.432 & 0.787 & & & & & & \\
BDRTN & 0.678 & 0.475 & 0.776 & & & & & \\
BCMT & 0.365 & 0.464 & 0.400 & 0.789 & & & & \\
EP & 0.331 & 0.390 & 0.441 & 0.552 & 0.811 & & & \\
GRNINV & 0.220 & 0.430 & 0.322 & 0.537 & 0.723 & 0.923 & & \\
GSCC & 0.310 & 0.329 & 0.450 & 0.652 & 0.597 & 0.771 & 0.880 & 0.890 \\
EP & 0.287 & 0.467 & 0.356 & 0.580 & 0.432 & 0.561 & 0.670 & 0.890 \\
\hline
\end{tabular}




\subsection{Inner Model Analysis}

Prior to inner model analysis, it is mandatory to estimate $\mathrm{R} 2$ values. The output suggested that the model explains the significant part of construct variance and has satisfactory homological validity based on the suggested criteria model ${ }^{[49]}$. Next, inner model path coefficients were calculated, which was done by calculating the path coefficients among the constructs to measure the structural model. The coefficients of the inner model path and outer loadings were measured by the performing bootstrap method ${ }^{[50]}$. The measures of path coefficients are presented in Table 3. The findings specify that all path coefficients are significant as the $t$ statistics values from the bootstrap method are greater than 2, which also supports our hypotheses H1 to H5.

Table 3 Results of inner path coefficients

\begin{tabular}{llcccc}
\hline \multicolumn{2}{c}{ Direct effect } & Original sample & Mean & SD & $t$ statistics \\
\hline BDACP & BDRTN & 0.518 & 0.531 & 0.0261 & 16.259 \\
BDASM & EP & 0.378 & 0.367 & 0.040 & 6.165 \\
BDASM & GRNINV & 0.469 & 0.469 & 0.062 & 8.187 \\
BDASM & BP & 0.364 & 0.363 & 0.087 & 3.443 \\
BDRTN & BDASM & 0.404 & 0.405 & 0.044 & 8.390 \\
BCMT & BDACP & 0.399 & 0.403 & 0.051 & 5.733 \\
BCMT & GSCC & 0.796 & 0.798 & 0.032 & 15.747 \\
GRNINV & EP & 0.557 & 0.663 & 0.052 & 8.012 \\
GRNINV & BP & 0.390 & 0.382 & 0.042 & 5.872 \\
GSCC & GRNINV & 0.523 & 0.521 & 0.031 & 7.128 \\
BDASM & EP & 0.153 & 0.155 & 0.002 & 3.972 \\
BDASM & BP & 0.167 & 0.171 & 0.004 & 4.132 \\
BDRTN & EP & 0.316 & 0.322 & 0.081 & 7.113 \\
BDRTN & GRNINV & 0.227 & 0.237 & 0.034 & 5.790 \\
BDRTN & BP & 0.211 & 0.211 & 0.325 & 5.112 \\
BCMT & BDASM & 0.123 & 0.126 & 0.004 & 3.523 \\
BCMT & EP & 0.143 & 0.150 & 0.082 & 3.211 \\
BCMT & GRNINV & 0.902 & 0.897 & 0.061 & 8.234 \\
BCMT & BP & 0.975 & 0.963 & 0.780 & 9.170 \\
GSCC & EP & 0.183 & 0.192 & 0.135 & 8.321 \\
GSCC & BP & 0.220 & 0.234 & 0.412 & 6.600 \\
\hline
\end{tabular}




\subsection{Cluster Analysis}

Hypothesis $\mathrm{H} 6$ was tested through cluster analysis, which groups the banks according to relative green human resources management practices and exercise. The multi group analysis was also performed to estimate whether there exists significance among path coefficients of the groups.

$K$-means clustering technique was employed by specifying clusters while cluster seeds were randomly selected. The observations were allocated for each cluster by using similarity principles. The testing clusters vary (for example, two, three and four) for estimation of the suitable cluster to be adopted. The output clustered the banks into two groups. To be specific, 13 banks were labelled as low Green HR Training while the remaining 22 banks were clustered as the high Green HR Training.

After cluster analysis, the next step was to estimate path coefficients of the inner model for each group for the purpose of comparing the findings. It was observed that two direct path coefficients (green innovation to EP, and to bank performance) had a significant difference, and thus, H6 was supported. The path coefficient results are reported in Table 4, from which it can be seen that for indirect path coefficients, no significant difference exists. Then, the test was performed again for GHR management practices. Once again, 21 banks loaded in the cluster indicating banks with high GHR management practices and 14 banks represented the cluster of banks having low green HR management practices. Additionally, multi group analysis was performed. However, for path coefficients, no significant difference was detected.

Table 4 Results of multi-group analysis

\begin{tabular}{llllllllc}
\hline \multicolumn{1}{c}{ Effect } & $\begin{array}{l}\text { Path } \\
\text { Coef } \\
\text { (High) }\end{array}$ & $\begin{array}{l}\text { Path } \\
\text { Coef } \\
\text { (Low) }\end{array}$ & $\begin{array}{l}t \text {-Values } \\
(\text { High }\end{array}$ & $\begin{array}{l}t \text {-Values } \\
\text { (Low } \\
\text { HRT) }\end{array}$ & $\begin{array}{l}p \text {-Values } \\
\text { (High } \\
\text { HRT) }\end{array}$ & $\begin{array}{l}p \text {-Values } \\
\text { (Low } \\
\text { HRT) }\end{array}$ & $\begin{array}{l}p \text {-Values } \\
\text { High vs } \\
\text { Low) }\end{array}$ \\
\hline BDACP BDRTN & 0.468 & 0.582 & 10.616 & 11.451 & 0.001 & 0.000 & 0.824 \\
BDASM & EP & 0.283 & 0.312 & 3.333 & 3.213 & 0.012 & 0.000 & 0.843 \\
BDASM GRNINV & 0.387 & 0.531 & 5.622 & 6.194 & 0.002 & 0.000 & 0.864 \\
BDASM & BP & 0.257 & 0.269 & 2.651 & 3.744 & 0.000 & 0.001 & 0.965 \\
BDRTN BDASM & 0.368 & 0.412 & 4.567 & 5.318 & 0.002 & 0.000 & 0.687 \\
BCMT & BDACP & 0.276 & 0.337 & 3.246 & 4.523 & 0.011 & 0.002 & 0.772 \\
BCMT & GSCC & 0.545 & 0.611 & 12.203 & 11.773 & 0.021 & 0.000 & 0.516 \\
GRNINV & EP & 0.565 & 0.602 & 7.696 & 3.272 & 0.011 & 0.002 & 0.232 \\
GRNINV & BP & 0.433 & 0.513 & 7.767 & 3.315 & 0.001 & 0.032 & 0.198 \\
GSCC & GRNINV & 0.621 & 0.754 & 12.345 & 11.876 & 0.021 & 0.001 & 0.911 \\
\hline
\end{tabular}

\section{Discussion and Conclusion}

\subsection{Conclusion}

This study aims to examine how ASEAN banks are driven to develop SCs through their commitment, BDT integration, GHRM practices, and GSCM, and then further analyze how these banks leverage these constructs to improve their economics and EP. Furthermore, the 
current study has measured the impacts of GHRM practices on the integration of BDT with banks operational processes to strengthen the relationship between internal and external GSCM practices and their influence on banks sustainable performance. The following conclusions are drawn:

1) All the suggested constructs, namely, bank commitment, GI process, GSC collaboration, and GHRM collectively contribute to the sustainable performance and the overall performance of Asian banks through acceptance, assimilation, and routinization of BDAs Figure 2, which reinforces the findings of previous studies by [34, 51]. In this case, it was showed that the adoption of green banking practices by the banks creates environmental, social, and corporate benefits for the banks. The findings of this study (Table 1) suggest that the Asian banks can pick up the low hanging fruits of sustainable performance and development of SCs by harnessing effective analytics of $\mathrm{BD}$. Besides, these findings are compatible with the studies by $[16,17,52]$ suggesting that BDAs potentially contributes to organizational decision-making, achieves competitive advantage, and helps firms to become a frontier of innovation, competition, and productivity.

2) Banks commitment influences the acceptance, assimilation, and reutilization of BD, which alternatively improves the sustainable and operational performance of the organization (Table 3). These findings enhance those found by [53] and [54], which showed that the organizations committing to proper data monitoring of their clients could achieve operational efficiency and sustainability. In addition, our findings (Table 3) illustrate that those banks commitment further influences internal and external GSCM practices, which alternatively yields financial and environmental gains for the banks. These results are compatible with studies by $[23,55]$ and [56] on BDAs that suggests organizations boost their environmental and financial performance through their commitment towards BDAs.

3) There is a significant difference in the impact of GI on banks finance and EP between high and low green HR training of employees (Table 4). From this study, it was found that banks practicing GI represents better environmental and economic performance as the employees of these banks have received high levels of advance GHR training, which is justified by the fact that organizations that encourage their employees to realize green creativity achieve better environmental management ${ }^{[57]}$, which as a finding is consistent with studies by $[23,43]$ and [7]. Lastly, it was found (Table 4) that internal and external GSCM has a positive impact on banks EFP, which implies that the Asian banks can contribute to reducing the environmental impact through their operations provided they develop and implement GSCM practices, which ultimately will result in increased financial gains. These findings echo the previous studies by $[58,59]$, which shows that leveraging advance knowledge of GSCM practices achieves better economic and environmental performance for the organizations. Science, business, and most industrial sectors have already adopted big data technology for processing the enormous amount of data that they have collected ${ }^{[60]}$.

\subsection{Implications}

1) Theoretical Implications. Firstly, it contributes to advancing the knowledge about BDT and its influence to boost banks EFP. Secondly, it is conducive to the development of the knowledge pertaining to the role of GHR training to optimize the impact of GI on banks EFP. 
Lastly, this study adds significant knowledge to leveraging GSCM practices for the purpose of augmenting the EFP of banks.

2) Practical Implications. Firstly, it was suggested that for the banks, an exclusive and functional process should be adopted to integrate BDT into their strategic and operational architecture and then maximize their FP. Moreover, banks need to focus on utilizing relevant BDT to tap the diverse opportunities pertinent to business. Secondly, banks require the support and the commitment of top management in terms of practicing GSCM and GHRM to enhance their SCs. Alternatively, persistent commitment to internal GSCM practices and GHR training help banks stay competitive in a dynamic financial market. Moreover, it is suggested that for the banks, formal environmental policy at corporate and operational levels should be integrated, so that internal and external GSCM, GT, and GI continue to amplify SCs and FP. At last, based on the findings of this study, it is suggested that for the banks, technological challenges should be coped effectively with to assimilate BD since these challenges may negatively impact the banks when they focus on external GSCM and sustainable practices. The potential business opportunities and obstacles offered through sustainability and BD are manageable provided banks top management is committed to implementing GHR practices, especially encouraging the employees to carry out green creativity, as it will facilitate the adoption of green management, green technologies, and green operation, which are the essentials of enhancing EFP.

\subsection{Limitations and Suggestions for Future Research}

As with any other study, there are certain limitations associated with this study. The first limitation was the research design that was a single source survey questionnaire as a source of primary data. It was suggested that in future studies, using other methods of data collection, such as interviews along with the survey questionnaire may be better. The second limitation is the use of quantitative data and limited construct to analyze the linkage among bank commitment, big data analytics, GSCM practices, GHRM practices, GI, and SCs. For future studies, it is better to use an extended research framework and employ mix methods to analyze the data. Lastly, in our study, data from a limited number of banks has been collected, and all Asian regions were not included due to financial and time constraints. Hence, future studies may consider enlarging the sample size and collecting data from all the major banks situated in other Asian countries to truly depict the SCs of Asian banks.

\section{References}

[1] Xiong X, Zhang J, Jin X, et al. Review on financial innovations in big data era. Journal of Systems Science \& Information, 2016, 4(6): 489-504.

[2] Dong J, Dai W, Li J. Exploring the linear and nonlinear causality between internet big data and stock markets. Journal of Systems Science and Complexity, 2020, 33(3): 783-798.

[3] Huang L, Wu C, Wang B. Paradigm change of system security theory modeling from the perspective of big data. Systems Engineering - Theory \& Practice, 2018, 38(7): 1877-1887.

[4] Corbett C J. How sustainable is big data? Production and Operations Management, 2018, 27(9): 16851695.

[5] Seles P, Jabbour S, Fiorini C, et al. Business opportunities and challenges as the two sides of the climate change: Corporate responses and potential implications for big data management towards a low carbon society. Journal of Cleaner Production, 2018, 189: 763-774. 
[6] Hampton S E, Strasser C A, Tewksbury J J, et al. Big data and the future of ecology. Frontiers in Ecology and the Environment, 2013, 11(3): 156-162.

[7] Jabbour C, Jabbour S. Green human resource management and green supply chain management: Linking two emerging agendas. Journal of Cleaner Production, 2016, 112: 1824-1833.

[8] Liboni L B, Jabbour A, Devika K, et al. Sustainability as a dynamic organizational capability: A systematic review and a future agenda toward a sustainable transition. Journal of Cleaner Production, 2017, 142: 308322.

[9] Prez A, Bosque I R. The formation of customer csr perceptions in the banking sector: The role of coherence, altruism, expertise and trustworthiness. International Journal of Business \& Society, 2015, 16(1): 75-94.

[10] Zimmermann S. Same same but different: How and why banks approach sustainability. Sustainability, 2019, 11(8): $22-67$.

[11] Govindan K, Sarkis J, Jabbour C, et al. Eco-efficiency based green supply chain management: Current status and opportunities. European Journal of Operational Research, 2014, 233(2): 293-298.

[12] Acharya A, Pereira V, Singh S K, et al. Big data, knowledge co-creation and decision making in fashion industry. International Journal of Information Management, 2018, 42: 90-101.

[13] Jackson S E, Renwick D S, Jabbour C C, et al. State-of-the-art and future directions for green human resource management: Introduction to the special issue. German Journal of Human Resource Management, 2011, 25(2): 99-116.

[14] Singh S K, El-Kassar A N. Role of big data analytics in developing sustainable capabilities. Journal of Cleaner Production, 2019, 213(2): 1264-1273.

[15] Mikalef P, Pappas I O, Krogstie J, et al. Big data analytics capabilities: A systematic literature review and research agenda. Information Systems and e-Business Management, 2018, 16(3): 547-578.

[16] D'Angeac G D. Big data: The management revolution. Harvard Business Review, 2012, 90(10): 60-68.

[17] Manyika J. Big data: The next frontier for innovation, competition, and productivity. http://www. mckinsey.com/Insights/MGI/Research/Technology and Innovation/Big dataThe next frontier for innovation, 2011.

[18] Wamba S F, Gunasekaran A, Akter S, et al. Big data analytics and firm performance: Effects of dynamic capabilities. Journal of Business Research, 2017, 70: 356-365.

[19] Mikalef P, Krogstie J, Pappas I O, et al. Exploring the relationship between big data analytics capability and competitive performance: The mediating roles of dynamic and operational capabilities. Information \& Management, 2020, 57(2): 103-169.

[20] Jun S. Bayesian structural time series and regression modeling for sustainable technology management. Sustainability, 2019, 11(18): 45-49.

[21] Teece D J, Shuen P A. Dynamic capabilities and strategic management. Strategic Management Journal, 1997, 18(7): 509-533.

[22] Argote L. Organizational learning: Creating, retaining, and transferring knowledge. Norwell: Kluwer Academic Publishers, 1999.

[23] Gunasekaran A, Papadopoulos T, Dubey R, et al. Big data and predictive analytics for supply chain and organizational performance. Journal of Business Research, 2017, 70: 308-317.

[24] Nguyen T, Zhou L, Spiegler V, et al. Big data analytics in supply chain management: A state-of-the-art literature review. Computers \& Operations Research, 2018, 98: 254-264.

[25] Hazen B T, Overstreet R E, Cegielski C G. Supply chain innovation diffusion: Going beyond adoption. The International Journal of Logistics Management, 2012, 23(1): 119-134.

[26] Li G, Fan H, Lee P K, et al. Joint supply chain risk management: An agency and collaboration perspective. International Journal of Production Economics, 2015, 164: 83-94.

[27] Chang $\mathrm{C} \mathrm{H}$. The influence of corporate environmental ethics on competitive advantage: The mediation role of green innovation. Journal of Business Ethics, 2011, 104(3): 361-370.

[28] Chithambaranathan P, Subramanian N, Gunasekaran A, et al. Service supply chain environmental performance evaluation using grey based hybrid MCDM approach. International Journal of Production Economics, 2015, 166: 163-176.

[29] Chen C L, Zhang C Y. Data-intensive applications, challenges, techniques and technologies: A survey on Big Data. Information Sciences, 2014(275): 314-347.

[30] Song M, Cen L, Zheng Z, et al. How would big data support societal development and ES? Insights and 
practices. Journal of Cleaner Production, 2017, 142(2): 489-500.

[31] Yang E, Burger J, Peters M. Customer service management \& Hofstede's cultural dimensions in Australia, Brazil, China, Germany, Japan, Norway, and The Usa. Academy of Organizational Culture, Communications and Conflict, 2016.

[32] Zhao R, Liu Y, Zhang N, et al. An optimization model for green supply chain management by using a big data analytic approach. Journal of Cleaner Production, 2016, 142: 1085-1097.

[33] Akter S, Wamba S F, Gunasekaran A, et al. How to improve firm performance using big data analytics capability and business strategy alignment? International Journal of Production Economics, 2016, 182: 113-131.

[34] Masukujjaman M, Siwar C, Mahmud MR, et al. Bankers perception of green banking: Learning from the experience of Islamic banks in Bangladesh. Geografia-Malaysian Journal of Society and Space, 2017, 12(2): $144-153$.

[35] Carvalho H, Govindan K, Azevedo S G, et al. Modelling green and lean supply chains: An eco-efficiency perspective. Resources Conservation \& Recycling, 2017, 120: 75-87.

[36] Cheng T Y, Yue-Qi L I, Lin Y E, et al. Does the fit of managerial ability with firm strategy matters on firm performance. Journal of Asian Finance Economics and Business, 2020, 7(4): 9-19.

[37] Ibe-Enwo G, Igbudu N, Garanti Z, et al. Assessing the relevance of green banking practice on bank loyalty: The mediating effect of green image and bank trust. Sustainability, 2019, 11(17): 46-51.

[38] Liang H, Saraf N, Xue H Y. Assimilation of enterprise systems: The effect of institutional pressures and the mediating role of top management. MIS Quarterly, 2007, 31(1): 59-87.

[39] Kok J M, Uhlaner L M, Thurik A R. Professional HRM practices in family ownedmanaged enterprises. Journal of Small Business Management, 2006, 44(3): 441-460.

[40] Joseph H, Astrachan T A, Kolenko. A neglected factor explaining family business success: Human resource practices. Family Business Review, 1994, 7(3): 251-262.

[41] Geng Y. Market demand, green product innovation, and firm performance: Evidence from Vietnam motorcycle industry. Journal of Cleaner Production, 2013, 40: 101-107.

[42] Kline R B. Beyond significance testing. Washington DC: American Psychological Association, 2012.

[43] El-Kassar A N, Singh S K. Green innovation and organizational performance: The influence of big data and the moderating role of management commitment and HR practices. Technological Forecasting and Social Change, 2019, 144: 483-498.

[44] Papadopoulos T, Gunasekaran A, Dubey R, et al. Big data and analytics in operations and supply chain management: Managerial aspects and practical challenges. Production Planning \& Control, 2017, 28(1112): 873-876.

[45] Kamakura W A, Wedel M. Factor analysis and missing data. Journal of Marketing Research, 2000, 37(4): 490-498.

[46] Hair J F, Black W C, Babin B J, et al. Multivariate data analysis: A global perspective. Upper Saddle River NJ: Pearson Education, 2010.

[47] Forne U C, Larcker D F. Evaluating structural equation models with unobservable variables and measurement error. Journal of Marketing Research, 1981, 18(1): 39-50.

[48] Hulland J. Use of partial least squares (PLS) in strategic management research: A review of four recent studies. Strategic Management Journal, 2015, 20(2): 195-204.

[49] Chin W W. Issues and opinion on structural equation modeling. MIS Quarterly, 1998, 22(1): 1.

[50] Davison A C, Hinkley D V. Bootstrap methods and their application. Technometrics, 1997, 94(445): 216217.

[51] Nabila N, Iqbal M, Rifat A, et al. Exploring client perceptions and intentions in emerging economies: The case of green banking technology. International Journal of Asian Business and Information Management (IJABIM), 2018, 9(3): 14-34.

[52] Constantiou I D, Kallinikos J. New games, new rules: Big data and the changing context of strategy. Journal of Information Technology, 2015, 30(1): 44-57.

[53] Forbes B M. IoT and big data at caterpillar: How predictive maintenance saves millions of dollars. Forbes, February, 2017.

[54] Allen P. How disney saves energy and operating costs-walt disney world resort's energy-management program combines technology, people, and energy star. HPAC Engineering, 2005, 77(1): 30-35. 
[55] Dubey R, Gunasekaran A, Childe S J, et al. Can big data and predictive analytics improve social and environmental sustainability? Technological Forecasting \& Social Change, 2017, 144: 534-545.

[56] Papadopoulos T, Gunasekaran A, Dubey R, et al. The role of big data in explaining disaster resilience in supply chains for sustainability. Journal of Cleaner Production, 2017, 142: 1108-1118.

[57] Bos-Nehles A, Renkema M, Janssen M. HRM and innovative work behaviour: A systematic literature review. Personnel Review, 2017, 46(7): 1228-1253.

[58] Jabbour S, Vazquez-Brust D, Jabbour C, et al. Green supply chain practices and environmental performance in Brazil: Survey, case studies, and implications for B2B. Industrial Marketing Management, 2017, 66: 1328.

[59] Vanalle R M, Ganga D, Miller G, et al. Green supply chain management: An investigation of pressures, practices, and performance within the Brazilian automotive supply chain. Journal of Cleaner Production, 2017, 151: 250-259.

[60] Trakunphutthirak R, Cheung Y, Lee V C S. Conceptualizing mining of firms web log files. Journal of Systems Science and Information, 2017, 5(6): 489-510. 